\title{
NPY Signaling Inhibits Extended Amygdala CRF Neurons to Suppress Binge Alcohol Drinking
}

\author{
Kristen E. Pleil ${ }^{1,2}$, Jennifer A. Rinker ${ }^{2,3,7}$, Emily G. Lowery-Gionta ${ }^{1,2}$, Christopher M. $^{2}$ \\ Mazzone $^{2,4}$, Nora M. McCall ${ }^{1,2,8}$, Alexis M. Kendra ${ }^{1,2,9}$, David P. Olson ${ }^{5,10}$, Bradford B. \\ Lowell $^{5}$, Kathleen A. Grant ${ }^{6}$, Todd E. Thiele ${ }^{2,3}$, and Thomas L. Kash ${ }^{1,2,3}$ \\ ${ }^{1}$ Department of Pharmacology, University of North Carolina School of Medicine, Chapel Hill, NC \\ 27599, USA
}

${ }^{2}$ Bowles Center for Alcohol Studies, University of North Carolina School of Medicine, Chapel Hill, NC 27599, USA

${ }^{3}$ Department of Psychology, University of North Carolina, Chapel Hill, NC 27599, USA

${ }^{4}$ Curriculum in Neurobiology, University of North Carolina-Chapel Hill School of Medicine, Chapel Hill, NC 27599, USA

${ }^{5}$ Division of Endocrinology, Department of Medicine, Beth Israel Deaconess Medical Center and Harvard Medical School, Boston, MA 02115, USA

${ }^{6}$ Division of Neuroscience, Oregon National Primate Research Center, Oregon Health and Science University, Beaverton, OR 97006, USA

\section{Summary paragraph}

\begin{abstract}
Binge alcohol drinking is a tremendous public health problem because it leads to the development of numerous pathologies including alcohol abuse, and anxiety ${ }^{1-4}$. It is thought to do so by hijacking brain systems that regulate stress and reward, including neuropeptide Y (NPY) and corticotropin-releasing factor (CRF). The central actions of NPY and CRF play opposing functional roles in the regulation of emotional and reward-seeking behaviors; therefore, dysfunctional interactions between these peptidergic systems could play a role in the development of these pathologies. Here, we used converging physiological, pharmacological, and chemogenetic
\end{abstract}

\footnotetext{
Users may view, print, copy, and download text and data-mine the content in such documents, for the purposes of academic research, subject always to the full Conditions of use:http://www.nature.com/authors/editorial_policies/license.html\#terms

7 current affiliation: Department of Neurosciences, Medical University of South Carolina, Charleston, SC 29425

8 current affiliation: Graduate Program in Neuroscience, University of Minnesota, Minneapolis, MN 55455, USA

9 current affiliation: Master of Biotechnology Program, Northwestern University, Evanston, IL 60208, USA

10 current affiliation: Department of Pediatrics, University of Michigan Medical School, Ann Arbor, MI 48109, USA

Author contributions KEP wrote the manuscript, designed the study, performed all electrophysiological recordings, and performed in vivo behavioral pharmacology, in vivo DREADD DID experiments, and immunohistochemistry. JAR performed cannulation and DREADD viral injection surgeries and in vivo behavioral pharmacology and DREADD DID experiments. EGLG performed cannulation surgeries and in vivo behavioral pharmacology experiments. CMM performed cannulation surgeries, fluorescence/ confocal microscope images of DREADD expression, and pilot experiments for DREADD constructs and CNO doses used in this study. NMM performed RT-PCR and immunohistochemistry and bred $C R F-C r e$ and CRF-reporter mice. AMK performed cannulation surgeries and bred CRF-Cre and CRF-reporter mice. DPO and BBL generated the CRF-ires-Cre (CRH-ires-Cre) mice. KAG oversaw rhesus monkey experiments and provided monkey brain tissue. TET aided in the design of and oversaw all behavioral experiments. TLK helped design the study and write the manuscript, and oversaw all molecular biology, microscopy, and electrophysiology work. All authors edited the manuscript.
} 
approaches to identify a precise neural mechanism in the bed nucleus of the stria terminalis (BNST), a limbic brain region involved in pathological reward and anxiety behaviors, underlying the interactions between NPY and CRF in the regulation of binge alcohol drinking in both mice and monkeys. We found that NPY Y1 receptor (Y1R) activation in the BNST suppressed binge alcohol drinking by enhancing inhibitory synaptic transmission specifically in CRF neurons via a novel, $\mathrm{G}_{\mathrm{i}}$-mediated, PKA-dependent postsynaptic mechanism. Further, chronic alcohol drinking led to persistent alterations in Y1R function in the BNST of both mice and monkeys, highlighting the enduring, conserved nature of this effect across mammalian species. Together, these data provide both a cellular locus and signaling framework for the development of novel therapeutics for treatment of neuropsychiatric diseases, including alcohol use disorders.

\section{INTRODUCTION}

Binge alcohol drinking is the most common form of excessive alcohol consumption and contributes to a host of long-term negative health consequences, including alcohol dependence and anxiety disorders ${ }^{5-9}$. Repeated bouts of binge-induced alcohol intoxication followed by withdrawal are hypothesized to cause aberrant plasticity in brain regions that underlie reward-seeking behavior and stress responsivity, leading to an increased negative affective state that drives increased alcohol consumption ${ }^{5,9-11}$. These effects may be mediated by altered signaling of endogenous stress and anti-stress neuropeptide systems that functionally oppose each other, particularly corticotropin-releasing factor (CRF) and neuropeptide $\mathrm{Y}(\mathrm{NPY})^{10,12-14}$. Central CRF signaling is recruited during binge alcohol drinking, enhances alcohol drinking and anxiety behavior, and is altered in rodent models of alcohol dependence ${ }^{15-18}$. In contrast, NPY signaling, primarily via its Y1 receptor (Y1R), blunts binge alcohol drinking and reduces anxiety 10, 19-21; however the neural locus of these peptidergic effects is unknown. The bed nucleus of the stria terminalis (BNST) is a limbic brain structure enriched with CRF and NPY that is a site of integration of stress and reward information $^{22,23}$ and may mediate the negative affective state associated with chronic alcohol use. Pharmacological manipulations in the BNST can alter alcohol drinking behaviors $^{24,25}$ and chronic alcohol exposure and withdrawal alter the function and plasticity of BNST neurons ${ }^{26,27}$, however the role of NPY signaling in the BNST to regulate alcohol drinking has not been evaluated.

\section{RESULTS}

\section{Y1R activation in the BNST suppresses binge alcohol drinking}

To begin to address these issues, we first examined how pharmacological manipulations of the NPY system in the BNST specific to signaling at its primary receptors, NPY-Y1 receptors (Y1R) and NPY-Y2 receptors (Y2R), alter binge alcohol drinking in C57BL/6J mice using the well-described "Drinking in the Dark" model of binge-like alcohol drinking ${ }^{28}$ (Fig. 1a, Supplementary Fig. 1a). We used both agonists and antagonists to assess function associated with receptor activation and endogenous NPY tone, respectively (Fig. 1, Supplementary Figs. 1,2). We found that infusion of a Y1R agonist into the BNST, but not adjacent dorsal striatum, reduced binge alcohol consumption (Fig. 1b,c, Supplementary Fig. 1b, Supplementary Fig. 2a), while infusion of a Y1R antagonist into the BNST increased 
alcohol consumption (Supplementary Fig. 1c,d), consistent with our hypothesis that Y1R in the BNST is a neural substrate for NPY's anti-drinking effects. Interestingly, the effect of the Y1R antagonist did not emerge until the second half of the binge drinking session, suggesting that endogenous NPY signaling is recruited across the binge drinking session. Neither Y1R modulator in the BNST altered anxiety-like or locomotor behavior in the open field test (OF) or sucrose consumption (Fig. 1d-f, Supplementary Fig. 1e-g, Supplementary Fig. 2b), suggesting that the behavioral effects of Y1R manipulation were specific to binge alcohol drinking. In contrast, intra-BNST infusion of the Y2R agonist increased alcohol consumption but decreased sucrose consumption without altering OF behavior (Supplementary Fig. 1h-1). Moreover, bilateral infusion of the Y2R antagonist had no measurable effects on behavior (Supplementary Fig. 1m-q; Supplementary Fig. 2c,d). These results suggest that manipulation of Y2R in the BNST may alter general reward-seeking/ appetitive behaviors rather than binge alcohol drinking as Y1R does.

\section{Mechanism of Y1R-mediated postsynaptic inhibition of BNST neurons}

We next investigated the synaptic mechanisms by which this specific Y1R-mediated suppression of alcohol drinking occurs using slice electrophysiology. We found that Y1R activation with the Y1R agonist enhanced the frequency of miniature inhibitory postsynaptic currents (mIPSCs) but not miniature excitatory postsynaptic currents (Fig. 1g-j). This result suggested a presynaptic locus of Y1R potentially to directly increase GABA release from presynaptic terminals, in direct competition with the previously characterized function of presynaptic Y2R in the BNST of inhibiting presynaptic GABA release ${ }^{13}$. However, Y1R has typically been described as a postsynaptic $\mathrm{G}_{\mathrm{i} / \mathrm{o}}$-coupled receptor ${ }^{29,30}$. Therefore to characterize the locus and mechanism of Y1R here in the BNST, we used selective inhibitors of canonical G protein-coupled receptor (GPCR) signaling pathways in the extracellular bath (Supplementary Fig. 3a) and directly in the postsynaptic neuron (Fig. 1k). Disruption of $\mathrm{G}_{\mathrm{S}} / \mathrm{G}_{\mathrm{i}}$ signaling with bath application of the PKA inhibitor Rp-Adenosine $3^{\prime}$, 5 -cyclic monophosphorothioate triethylammonium salt (Rp-cAMPs, $10 \mu \mathrm{M}$ ) blocked the ability of LeuPro NPY to increase mIPSC frequency, while disruption of the canonical $\mathrm{G}_{\mathrm{q}}$ signaling pathway with the PLC inhibitor 1-[6-[[(17ß)-3-Methoxyestra-1,3,5(10)-trien-17yl]amino]hexyl]-1H-pyrrole-2,5-dione (U73122; $10 \mu \mathrm{M}$ ), did not (Supplementary Fig. 3a), providing evidence that $\mathrm{Y} 1 \mathrm{R}$ is a $\mathrm{G}_{\mathrm{i}}$-coupled receptor. However, additional experiments using postsynaptic-specific manipulations of GPCR signaling indicated that Y1R activation increased GABAergic transmission via a postsynaptic, protein kinase A (PKA)-dependent, mechanism. Inclusion of the non-hydrolyzable GDP analog guanosine $5^{\prime}-[\beta-$ thio]diphosphate trilithium salt (GDP $\beta \mathrm{S}, 1 \mathrm{mM}$ ) to block postsynaptic GPCR activity, the vesicle fusion blocker and potent inhibitor of $\mathrm{G}_{\mathrm{i}}$ signaling N-ethylmaleimide (NEM, $50 \mu \mathrm{M}$ ), and the PKA inhibitor fragment (6-22) amide (PKI, $20 \mu \mathrm{M}$ ) to inhibit PKA signaling in the recording pipette all blocked the ability of bath-applied LeuPro NPY to increase mIPSC frequency, while the calcium chelator 1,2-Bis(2-aminophenoxy)ethane- $N, N, N^{\prime}, N^{\prime}$-tetraacetic acid (BAPTA, $10 \mu \mathrm{M}$ ) did not (Fig. 1k). Analysis of basal mIPSC frequency in these experiments suggests that the ability of the Y1R agonist to increase mIPSC frequency was independent of basal frequency (Supplementary Fig. 3b). 
Because activation of postsynaptic Y1R non-canonically increased mIPSC frequency, rather than amplitude, we evaluated the possible mechanisms of this effect, including alterations in postsynaptic excitability, activation of a retrograde signal to enhance presynaptic GABA release, and modulation of postsynaptic GABA receptor function. Analysis of membrane resistance during mIPSC experiments suggested that Y1R activation did not change cell membrane conductance (Supplementary Fig. 3c). Further, Because Cs can block $\mathrm{K}^{+}$ channels, we also evaluated the effect of LeuPro NPY on mIPSCs using a Cs-based intracellular solution in the recording pipette rather than a $\mathrm{K}^{+}$-based solution. We found a similar effect of the Y1R agonist on mIPSC frequency (20.2 $\pm 6.4 \%)$, suggesting that Y1R activation was not altering the conductance of dendritic potassium channels (Supplementary Fig. 3d). Next, we examined whether Y1R activates a retrograde messenger or alters postsynaptic GABA receptor function. Y1R activation enhanced IPSCs mediated by superphysiological exogenous application of GABA $(100 \mu \mathrm{M})$ directly to the postsynaptic neuron, which was ablated by a $\mathrm{GABA}_{\mathrm{A}} \mathrm{R}$ antagonist (Fig. 11), demonstrating that Y1R modulation of postsynaptic GABA responses was present when presynaptic GABA release was occluded and suggesting that the Y1R effect was not via activation of a retrograde signal but via enhancement of postsynaptic $\mathrm{GABA}_{\mathrm{A}} \mathrm{R}$ function. Further, blocking postsynaptic fusion of newly-trafficked postsynaptic $\mathrm{GABA}_{\mathrm{A}} \mathrm{Rs}$ to the membrane with the intracellular inhibitor of protein transport to the Golgi apparatus brefeldin A (BFA, $200 \mathrm{nM})$ prevented the effect of the Y1R agonist on mIPSC frequency, while blocking endocytosis of postsynaptic $\mathrm{GABA}_{\mathrm{A}}$ Rs with dynamin inhibitory peptide (DIP, 2mM; Fig. 1k) had no effect. Together, these results suggest that in the BNST, Y1R is a postsynaptic $\mathrm{G}_{\mathrm{i}}$-coupled GPCR that increases the surface expression of postsynaptic $\mathrm{GABA}_{\mathrm{A}}$ Rs by inhibiting PKA activity, a previously undescribed mechanism of inhibitory plasticity.

\section{Receptor-specific circadian regulation of endogenous NPY signaling}

Because C57BL/6J mice are nocturnal and binge drink during the dark phase of the light cycle $^{18,31}$, we next tested the hypothesis that chronic binge alcohol drinking disrupts NPY signaling in the BNST. While endogenous NPY levels and function have been shown to fluctuate across the light cycle in many brain regions ${ }^{32}$, we found that there were no circadian oscillations in NPY levels or basal GABAergic transmission in the BNST (Fig. 2a-d). However, NPY modulation of GABAergic transmission was different across the light cycle (Fig. 2e-f). Both the Y1R and Y2R agonists altered mIPSC frequency, but not amplitude, during the light phase of the light cycle but not the dark phase (Fig. 2c). Preapplication of a Y1R antagonist blocked the effect of subsequently-applied Y1R agonist ( $\mathrm{p}>$ $0.90)$, but not the $\mathrm{Y} 2 \mathrm{R}$ agonist $(\mathrm{t}(4)=3.32, \mathrm{p}=0.029)$, confirming the receptor specificity of the Y1R-mediated effect (data not shown). Interestingly, the Y1R antagonist did not modulate GABAergic transmission during either phase of the light cycle, but the Y2R agonist increased mIPSC frequency during the dark phase, but not light phase, of the light cycle (Fig. 2f). Circadian regulation of Y2R antagonist effects on GABAergic transmission during suggests that NPY receptors may be more highly expressed or functionally upregulated during the dark phase, leading to greater endogenous receptor-mediated NPY tone that may occlude the effects of exogenously applied NPY agonists. The inability of the $\mathrm{Y} 1 \mathrm{R}$ antagonist to alter GABAergic transmission during the dark phase may be due to more rapid desensitization of $\mathrm{Y} 1 \mathrm{R}$ compared to $\mathrm{Y} 2 \mathrm{R}^{33}$. Furthermore, increased NPY tone during 
the dark phase may be related to circadian regulation of binge ethanol drinking. Altogether, these results suggest that there is greater NPY receptor expression and receptor-mediated endogenous NPY tone during the dark phase of the cycle, when mice binge drink alcohol.

\section{Chronic binge drinking alters circadian regulation of Y1R function}

We tested the hypothesis that circadian regulation in receptor-specific NPY function in the BNST may be important for Y1R modulation of binge alcohol drinking and that the negative behavioral consequences of chronic binge drinking may be mediated by loss of circadian control of Y1R-mediated NPY signaling in the BNST. One day after three cycles of binge drinking in the DID paradigm (Fig. 3a, Supplementary Fig. 4a), BNST neurons of mice that drank ethanol (EtOH) had greater basal spontaneous IPSC frequency, but not amplitude, than those of water-drinking controls (CON), while mIPSC frequency and amplitude were not different between groups (Fig. 3b). As observed in experiments with naïve mice (Fig. 2), $\mathrm{Y} 1 \mathrm{R}$ and $\mathrm{Y} 2 \mathrm{R}$ agonists did not modulate GABAergic transmission in BNST neurons of CONs during the dark phase of the light cycle; however, they did in EtOH mice (Fig. 3c-d). In addition, Y1R modulation of inhibitory synaptic transmission in 3-cycle EtOH mice could be blocked by intracellular inclusion of a PKA inhibitor (Fig. 3k), suggesting an upregulation of the Y1R mechanism characterized above. Consistent with these effects, both Y1R and Y2R protein expression, but surprisingly not NPY expression, were greater in the BNST of EtOH mice than CONs at this time point (Fig. 3e-g). Because there was no alteration in the mRNA of NPY, Y1R, or Y2R (Supplementary Fig. 4b-d), this increase in receptor protein expression and function following chronic binge alcohol drinking is likely translation-dependent. Interestingly, NPY protein expression was decreased immediately following the last binge ethanol session of either 1-cycle or 3-cycle EtOH DID compared to CONs (Fig. 3h), suggesting that the endogenous NPY system is acutely recruited during each binge ethanol drinking session. In order to determine whether increased Y1R function following 3-cycle DID was merely an acute response to this NPY recruitment and depletion that occurs during each binge ethanol drinking session or whether it requires repeated cycles of binge drinking and withdrawal, we also examined Y1R modulation of inhibitory synaptic transmission one day after 1-cycle DID. We found that Y1R activation with LeuPro NPY did not alter GABAergic transmission after a single cycle of DID (Fig. 3k) as it did after three cycles, suggesting that the upregulation of Y1R function may be an adaptive response that develops across repeated cycles of binge drinking to compensate for the allostatic burden imposed on the mice from repeated acute recruitment and depletion of NPY that occurs with each binge drinking episode. Further, the enhancement of Y1R function observed after three cycles of binge drinking persisted up to 10 days following the final binge drinking episode (Fig. 3k), suggesting that this was a long-lasting change in function of the NPY system. To determine the translational potential of these findings, we also investigated how chronic alcohol drinking in non-human primates alters $\mathrm{Y} 1 \mathrm{R}$ signaling in the BNST using a well-established model of voluntary, long-term ethanol selfadministration in adult male rhesus macaques ${ }^{34}$ (Fig. 3i). Consistent with mouse experiments, Y1R activation with LeuPro NPY increased GABAergic transmission in BNST neurons of chronic binge-drinking, but not control monkeys (Fig. 3j,k). Together, these data show that dysregulation of Y1R-mediated endogenous NPY signaling in the BNST is an 
enduring effect of chronic alcohol use that develops prior to physical dependence but persists during long-term binge alcohol drinking and across mammalian species.

\section{Postsynaptic modulation by Y1R in the BNST is specific to CRF neurons}

When we examined the effect of Y1R activation on GABAergic transmission in the BNST of naïve mice, we noted a considerable amount of variability in the magnitude of the effect across individual neurons, which has also been reported in the basolateral amygdala ${ }^{29}$. Because CRF has been shown to increase alcohol drinking in mice ${ }^{16,35}$, the opposite phenotype that we found with Y1R activation in the BNST, and both peptides are densely expressed in the BNST ${ }^{13}, 36$, we hypothesized that $\mathrm{Y} 1 \mathrm{R}$ activation in the BNST decreases binge alcohol drinking by directly inhibiting CRF neurons. We first evaluated the ability of $\mathrm{Y} 1 \mathrm{R}$ activation to alter synaptic function at CRF neuron synapses using slice electrophysiology in the BNST of CRF-reporter mice (Fig. 4a,b). CRF+ neurons had greater mIPSC amplitude, but not frequency, than CRF- neurons (Fig. 4c,d). Y1R activation with bath application of LeuPro NPY greatly increased mIPSC frequency in CRF+ neurons by $54.7 \pm 19.3 \%$ but did not alter mIPSC frequency in CRF- neurons $(-1.3 \pm 7.8 \%$; Fig. $4 \mathrm{e})$, suggesting that the effects of Y1R in the BNST are specific to CRF neurons. Further, LeuPro NPY decreased the amplitude of mIPSCs in CRF+, but not CRF-, neurons by a small but significant amount (Fig. 4f) and increased the decay time of mIPSC events in CRF + neurons but not CRF- neurons (Fig. 4g). Analysis of the cumulative probability distribution of mIPSC events confirmed that Y1R activation led to an increase in smalleramplitude mIPSCs in CRF+ but not CRF- neurons (Fig. 4h). Together, results suggest that activation of postsynaptic Y1R on CRF neurons in the BNST results in the insertion of $\mathrm{GABA}_{\mathrm{A}}$ Rs with longer decay kinetics, such as those with $\mathrm{a}_{2 / 3}$ subunits, leading to more smaller-amplitude IPSCs with longer decay.

\section{Direct in vivo chemogenetic activation of $\mathrm{G}_{\mathrm{i}}$ signaling in BNST CRF neurons suppresses binge drinking}

Our results indicate that $\mathrm{G}_{\mathrm{i}}$-coupled $\mathrm{Y} 1 \mathrm{Rs}$ may be specifically expressed postsynaptically on CRF neurons in the BNST, where they function to decrease binge alcohol drinking by enhancing synaptic inhibition of CRF neurons (depicted in the model in Supplementary Fig. 5a). We directly tested this hypothesis by evaluating whether in vivo activation of $\mathrm{G}_{\mathrm{i}}$ signaling in CRF neurons in the BNST decreases binge alcohol consumption. We injected the BNST of CRF-ires-Cre (CRF-Cre) knock-in mice backcrossed to a C57BL/6J background with either a virus containing a Cre-dependent $\mathrm{G}_{\mathrm{i}}$-coupled designer receptor activated by designer drug $\left(\mathrm{G}_{\mathrm{i}}\right.$-DREADD) or a control vector ${ }^{37}$ (Fig. 5a,b). Selective chemogenetic activation of the $\mathrm{G}_{\mathrm{i}}$-DREADD with bath application of the designer drug clozapine-N-oxide (CNO) during slice electrophysiology recordings hyperpolarized $\mathrm{G}_{\mathrm{i}^{-}}$ DREADD-expressing CRF-Cre neurons in the BNST, confirming that this manipulation functionally inhibits $\mathrm{CRF}$-Cre neurons (Supplementary Fig. 5b,c). In vivo systemic administration of CNO prior to ethanol access on Day 4 Cycle 3 of DID suppressed binge alcohol consumption in $\mathrm{G}_{\mathrm{i}}$-DREADD mice but not control vector (CON) mice (Fig. 5c), recapitulating the effect of Y1R activation in the BNST (Fig. 1b). Intriguingly, CNO injection before OF decreased anxiety-like behavior in $\mathrm{G}_{\mathrm{i}}$-DREADD mice but not CONs (Fig. 5d) without altering locomotor behavior (Fig. 5e), altogether suggesting that alterations 
in binge alcohol drinking and anxiety by manipulation of $\mathrm{G}_{\mathrm{i}}$ signaling in CRF neurons were not due to non-specific locomotor effects of CNO.

Because in vivo inhibition of PKA via activation of $G_{i}$ signaling in BNST CRF neurons reduced binge drinking and anxiety, we also tested whether stimulation of PKA via activation of $\mathrm{G}_{\mathrm{S}}$ signaling was sufficient to increase the expression of these behaviors using an identical experimental procedure as for $\mathrm{G}_{\mathrm{i}}$ signaling (Fig. 5 f,g). $\mathrm{CNO}$ administration did not alter binge alcohol drinking or OF behavior in mice with the $\mathrm{G}_{\mathrm{s}}-\mathrm{DREADD}$ or CON vector (Fig. 5h-j). However, when mice received both CNO and intra-BNST infusion of the Y1R agonist LeuPro NPY on a subsequent cycle of binge drinking, activation of the $\mathrm{G}_{\mathrm{s}^{-}}$ DREADD blocked the ability of the Y1R agonist to suppress binge alcohol drinking (Fig. $5 \mathrm{k}$ ). This suggests that stimulation of PKA in BNST CRF neurons via $\mathrm{G}_{\mathrm{s}}$ activation is sufficient to block the PKA-inhibiting mechanism by which Y1R activation regulates binge drinking. This finding provides further in vivo evidence that the mechanism of Y1Rmediated inhibition of BNST CRF neurons we characterized using ex vivo electrophysiology is the mechanism by which Y1R suppresses binge alcohol drinking.

\section{DISCUSSION}

This is the first report to provide direct evidence that NPY signaling and CRF neurons in the BNST are involved in the regulation of binge alcohol drinking. Many previous reports have demonstrated that NPY and CRF produce divergent alcohol-drinking phenotypes ${ }^{20,35}$, and our data suggest that this may be due to their opposing functional roles in the BNST. Further, the anti-drinking effects of NPY are produced by its direct inhibition of BNST CRF neurons via Y1R, suggesting a specific anatomical and synaptic locus for the interaction between these two peptides. Interestingly, a role for postsynaptic Y1R-mediated inhibition has also recently been reported for the basolateral amygdala ${ }^{29}$, where it is involved in reducing anxiety. However, here we found a novel, non-canonical postsynaptic mechanism by which Y1R activation increased the frequency of postsynaptic inhibitory currents, suggesting that $\mathrm{Y} 1 \mathrm{R}$ signaling potentiates postsynaptic $\mathrm{GABA}_{\mathrm{A}} \mathrm{R}$ responses, altering plasticity at inhibitory synapses on CRF neurons in the BNST. Given the extensive literature describing the roles of GABARs and CRF in alcohol drinking and dependence $^{16,18,35,38-43}$, strict modulation of the function and plasticity of GABARs on CRF neurons in the BNST by Y1R may be particularly important for maintaining homeostasis of CRF neuronal activity. Thus, alterations of normal NPY function, such as those after chronic binge alcohol drinking, may have profound consequences on long-term behavioral outcomes, including continued alcohol use that leads to dependence.

We found that the endogenous NPY system was acutely recruited across each binge alcohol drinking session and that as few as three cycles of binge alcohol drinking in rodents, before the development of alcohol dependence ${ }^{44}$, drastically and chronically altered the NPY system in the BNST for at least 10 days after the last binge episode. We observed the same adaptation of Y1R in the BNST of long-term alcohol-drinking rhesus monkeys, suggesting that this adaptation is a common adaptation across voluntary ethanol administration paradigms, states of alcohol dependence, and species. This is supported by pharmacological and genetic studies that implicate the regulation of NPY in alcohol 
dependence $\mathrm{e}^{1,3,20,21,45,46}$. The persistence of this widely-observed consequence of binge alcohol drinking suggests that Y1R, or more broadly, inhibition of CRF neuron function, may be an effective pharmacotherapeutic target for the prevention and treatment of alcohol abuse.

\section{ONLINE METHODS}

\section{Subjects}

Adult male C57BL/6J mice acquired from Jackson Laboratory (Bar Harbor, ME) were six weeks old at beginning of the study. $C R F$-ires-Cre (CRF-Cre, also termed CRH-ires-Cre) mice were generated using bacterial artificial chromosome (BAC) recombineering techniques as described previously ${ }^{47}$. Briefly, an optimized internal ribosome entry sequence fused with a Cre transgene and FRT-flanked neomycin resistance cassette was targeted three bases after the stop codon of the $C R F$ gene contained in a BAC. The final targeting construct contained approximately $4 \mathrm{~kb}$ of flanking sequence on either side of the Cre cassette. Following electroporation into ES cells, positive clones were identified by long range PCR and confirmed by southern blotting. Appropriately targeted ES cells were injected into blastocysts and chimeric animals were generated by the Beth Israel Deaconess Transgenic core. Germline transmission of the targeted transgene was confirmed by PCR of tail DNA using the following primer sequences: CRFstopF2:

GATCTCACCTTCCACCTTCTG, CRHstopR2: CAAAGGTTTCCTCCTTGGGG and iresR2: CACACCGGCCTTATTCCAAGC. After confirming germline transmission, the CRF-ires-Cre mice were crossed to a Rosa26-Flpe deleter mouse (JAX stock 003946) to delete the Frt-flanked neo cassette. Deletion of the neo cassette was confirmed by PCR. $C R F$-Cre mice were backcrossed onto a C57BL/6J strain in order to maintain consistency with experiments performed in wildtype mice. For some electrophysiology experiments, CRF-Cre mice were crossed with floxed Ai3 (CAGFloxed EYFP) or floxed Ai9 (CAGFloxed tdTomato) mice acquired from Jackson Laboratory (Bar Harbor, ME) to allow $a$ priori identification of CRF neurons with fluorescent proteins.

Mice used for signaling and reverse light cycle studies were group-housed, and mice in drinking experiments were singly-housed, in colony rooms with 12:12 hr light-dark cycle with lights on at 7 a.m. or 7 p.m. Mice had ad libitum access to rodent chow and water. All procedures were approved by the Institutional Animal Care and Use Committee of the University of North Carolina at Chapel Hill and performed in accordance with the National Institutes of Health guide for the care and use of laboratory animals.

\section{Drinking in the Dark experiments}

We used the four-day Drinking in the Dark procedure (DID; Fig. 1a, Supplementary Fig. 1a), which is a well-established animal model of human binge drinking that generates high ethanol intake and blood ethanol concentrations ( $\geq 80 \mathrm{mg} / \mathrm{dl}$ ) and has been used to characterize neuromodulators of binge-like alcohol consumption ${ }^{18,35}$. Three $\mathrm{h}$ into the dark cycle, water bottles were replaced with bottles containing a $20 \%(\mathrm{v} / \mathrm{v})$ ethanol solution for 2 $\mathrm{h}$ on Days 1-3 and $4 \mathrm{~h}$ on Day 4. For all experiments involving multiple cycles of DID procedures, each cycle was separated by $3 \mathrm{~d}$ of abstinence. 
First, we examined whether bilateral intra-BNST administration of the following selective NPY receptor modulators could decrease binge alcohol drinking in four distinct experiments using separate cohorts of mice (Fig. 1a): Y1R agonist [ $\left[\mathrm{Leu}^{31} \mathrm{Pro}^{34}\right]$-Neuropeptide Y (LeuPro NPY; 99 pmol/200 nL/side), Y1R antagonist BIBP 3226 (20 pmol/200 nL/side), Y2R agonist NPY 13-36 (100 pmol/200 nL/side), and Y2R antagonist BIIE 0246 (120 $\mathrm{pmol} / 200 \mathrm{~nL} / \mathrm{side}$ ). First, mice underwent one cycle of DID to establish baseline binge drinking levels. Then mice were implanted with cannulae aimed at the dorsal BNST (with respect to Bregma - AP: $+0.3 \mathrm{~mm}, \mathrm{ML}: \pm 1.1 \mathrm{~mm}, \mathrm{DV}:-4.35 \mathrm{~mm}$ ) under an anesthetic cocktail of ketamine $(110 \mu \mathrm{mg} / \mathrm{kg})$ and xylazine $(10 \mu \mathrm{mg} / \mathrm{kg})$, with the aid of the Leica Angle Two stereotaxic instrument (Leica Microsystems Inc, Buffalo Grove, IL). After $10 \mathrm{~d}$ of recovery from surgery and habituation to the head caps, mice underwent Cycles 2 and 3 of DID. For all four experiments, mice received bilateral intra-BNST injections of vehicle (10\% DMSO in sterile water $\left(\mathrm{sH}_{2} 0\right)$ or in $0.9 \%$ saline, depending on compound administered on Cycle 3 challenge) two hr before ethanol access on the fourth, binge test day of Cycle 2 using a 33-gauge micro-injection needle (Hamilton Company, Reno, NV) at a rate of $100 \mathrm{~nL} / \mathrm{min}$. The micro-injection needle was left in place for one min post-infusion to allow for adequate diffusion of the drug away from the injector tip. On Day 4 Cycle 3, mice received intra-BNST infusions of LeuPro NPY or $\mathrm{sH}_{2} 0$ vehicle (Experiment 1), BIBP 3226 or $\mathrm{sH}_{2} 0$ vehicle (Experiment 2), NPY 13-36 or saline vehicle (Experiment 3), and BIIE 0246 or $\mathrm{sH}_{2} \mathrm{O}$ vehicle (Experiment 4). Placement into the drug or control group was determined in a pseudo-random fashion so that the two groups had similar means and SEM for baseline ethanol drinking. Ten days after DID, mice within the cohort received the opposite infusion solution before the open field test (OF). Ten days later, mice underwent a cycle of DID with $10 \%$ sucrose instead of ethanol, and they were randomly assigned within the cohort to receive drug or vehicle. Experiments were replicated for LeuPro NPY and BIIE 0246 after 2-cycle DID in separate cohorts of mice (Supplementary Fig. 2).

Experiments to examine the effect of direct in vivo activation of $\mathrm{G}_{\mathrm{i}}$ or $\mathrm{G}_{\mathrm{S}}$ signaling in BNST CRF neurons were conducted similarly (Fig. 5a,f) but used both male and female CRF-Cre mice. Because effects were always present in either both or neither sex, and no differences were observed between sexes, mice were combined for all data presented. After one cycle of DID, $C R F$-Cre mice received intra-BNST (with respect to Bregma - AP: $+0.3 \mathrm{~mm}$, ML: $\pm 1.1 \mathrm{~mm}$, DV: $-4.35 \mathrm{~mm}$ ) microinjections of a virus containing a Cre-dependent $\mathrm{G}_{\mathrm{i}}$-coupled designer receptor activated by designer drug ( $\mathrm{G}_{\mathrm{i}}$-DREADD), AAV8-hSyn-DIO-hM4DmCherry, or a control vector, AAV8-hSyn-DIO-mCherry, under an anesthetic cocktail of ketamine $(100 \mu \mathrm{mg} / \mathrm{kg})$ and xylazine $(10 \mu \mathrm{mg} / \mathrm{kg})$. Virus was infused at a rate of $100 \mathrm{~nL} / \mathrm{min}$ for $5 \mathrm{~min}$ (400-500 $\mathrm{nL}$ total volume each side), and microinjection needles were left in place for 10 min post-infusion. After $\sim 10 \mathrm{~d}$ recovery, mice underwent a second cycle of DID with $\mathrm{NaCl}$ (saline) injections (0.9\%, i.p. on Days 1-3, plus 0.5\% DMSO on Day 4) administered 40 min before ethanol access each day. On the next cycle of DID, mice were administered clozapine N-oxide (CNO; $3 \mathrm{mg} / \mathrm{kg}$, i.p on Day 4), the selective DREADD agonist, instead of vehicle, before ethanol access on the fourth day. Thus, $\mathrm{CNO}$ was not delivered until the DREADD virus had been in the BNST for at least three weeks to allow for maximal transduction of the viral vector and incorporation and expression of the DREADD receptors ${ }^{37}$. Two weeks later, mice were given $\mathrm{CNO}$ (3 mg/kg, i.p.) immediately before an 
open field test. Because CNO activation of the DREADD requires approximately $40 \mathrm{~min}$, the first $40 \mathrm{~min}$ of $\mathrm{OF}$ was used as a baseline to compare to behavior during the activated DREADD. A similar experiment was carried out for examination of $\mathrm{G}_{\mathrm{s}}$ signaling in BNST CRF neurons using a $\mathrm{G}_{\mathrm{s}}$-coupled DREADD virus (AAV8-hSyn-DIO-rM3D-mCherry; $\mathrm{G}_{\mathrm{s}}{ }^{-}$ DREADD) or control mCherry vector. Mice in the $\mathrm{G}_{\mathrm{s}}$-DREADD experiment were subsequently bilaterally cannulated in the BNST and then they underwent an additional cycle of EtOH DID. On the binge test day, mice received CNO (3 mg/kg, i.p.) $180 \mathrm{~min}$ prior to ethanol access, LeuPro NPY (99pmol/200nL/side, inta-BNST) $140 \mathrm{~min}$ prior to ethanol access, and a CNO booster ( $3 \mathrm{mg} / \mathrm{kg}$, i.p.) $40 \mathrm{~min}$ prior to ethanol access. For in vivo pharmacology and DREADD experiments described above, mice were sacrificed following the last behavior and cannulae and virus injection placements were histologically verified (shown for DREADDs in Fig. 5b,g). Only mice with bilateral hits were included in data analysis, leading to exclusion of 0-4 mice per group across all experiments, except for the $\mathrm{G}_{\mathrm{s}}$-DREADD + LeuPro NPY experiment in which mice that had unilateral cannulae hits were included ( $\mathrm{n}=2 /$ group).

To examine the effects of binge alcohol drinking on the NPY system in the BNST, mice underwent one or three cycles of DID and were then sacrificed immediately, one day, or 10 $\mathrm{d}$ after the last binge session for electrophysiology, immunohistochemistry, or RT-PCR. Mice consumed 6.4-7.2 $\mathrm{g} / \mathrm{kg}$ on the binge ethanol test day across the three cycles, with corresponding high blood ethanol concentrations (BECs) of $162 \mathrm{mg} / \mathrm{dl}$ immediately following the Cycle 3 binge session (Supplementary Fig. 4a). This 3-cycle DID procedure has been shown to increase alcohol preference in a two-bottle choice paradigm without inducing alcohol dependence ${ }^{44}$

\section{Ethanol self-administration in rhesus monkeys}

We used schedule-induced polydipsia to induce voluntary, long-term ethanol selfadministration (ESA) in adult male rhesus monkeys (Macaca mulatta), as previously described $^{34,48}$. Briefly, monkeys were individually housed in stainless steel cages that allowed for visual, auditory, and olfactory sensory contact with each other in a colony room with 12:12 hr light-dark cycle with lights on at 7 a.m. Monkeys were trained to use operant panels in their cages that supplied all food, water, and ethanol, and all panel data were recorded with a National Instruments interface (Austin, TX). Then monkeys were trained daily to use the panel and induced to drink $0.0,0.5,1.0$, and $1.5 \mathrm{~g} / \mathrm{kg}$ ethanol (4\%) in $30 \mathrm{~d}$ epochs. Monkeys were subsequently allowed to voluntarily administer $4 \%$ ethanol and water ad libitum for $22 \mathrm{~h} / \mathrm{d}, 7 \mathrm{~d} / \mathrm{wk}$ for 12 calendar months before necropsy (at 5.5-8 yrs old). Daily average ethanol intake across monkeys ranged from 1.7 to $2.8 \mathrm{~g} / \mathrm{kg}$.

\section{Reverse light cycle signaling experiments}

To examine circadian oscillations in NPY signaling in the BNST, C57BL/6J mice were sacrificed approximately three hr after lights on or lights off in the colony room, and their brains were harvested for electrophysiology or immunohistochemistry experiments. This timing was consistent with all other experiments performed in the current study and with characterized timing of circadian fluctuations in NPY signaling in the hypothalamus ${ }^{32}$. Group assignment was random. 


\section{Slice electrophysiology}

We performed whole-cell voltage-clamp electrophysiological recordings in BNST neurons from acutely-prepared coronal brain slices of C57BL/6J mice, CRF-Cre reporter mice, and rhesus monkeys as previously described ${ }^{36}$ to examine the effects of NPY modulators on synaptic transmission in the BNST, with experimenters blind to experimental condition. Mice were decapitated under isoflurane anesthesia, and their brains were rapidly removed and placed in ice-cold sucrose-artificial cerebrospinal fluid (aCSF) containing (in mM) 194 sucrose, $20 \mathrm{NaCl}, 4.4 \mathrm{KCl}, 2 \mathrm{CaCl}_{2}, 1 \mathrm{MgCl}_{2}, 1.2 \mathrm{NaH}_{2} \mathrm{PO}_{4}, 10.0$ glucose, and 26.0 $\mathrm{NaHCO}_{3}$ saturated with $95 \% \mathrm{O}_{2} / 5 \% \mathrm{CO}_{2}$. Coronal slices $300 \mu \mathrm{m}$ in thickness containing the dorsal BNST (Bregma 0.26-0.02 mm) were sectioned on a Leica VT1200 vibratome and stored in a holding chamber of $28-30^{\circ} \mathrm{C}$, oxygenated ACSF containing (in mM) $124 \mathrm{NaCl}$, $4.4 \mathrm{KCl}, 2 \mathrm{CaCl}_{2}, 1.2 \mathrm{MgSO}_{4}, 1 \mathrm{NaH}_{2} \mathrm{PO}_{4}, 10.0$ glucose, and $26.0 \mathrm{NaHCO}_{3}$. Slices were transferred to a submerged recording chamber (Warner Instruments, Hamden, CT), where they were perfused with heated, oxygenated aCSF at a rate of approximately $2 \mathrm{ml} / \mathrm{min}$ and allowed to equilibrate for $30 \mathrm{~min}$ before electrophysiological recordings. For recordings in $C R F \mathrm{x}$ Ai3 mice, $C R F$-Cre-positive neurons were excited by a $490 \mathrm{~nm}$ LED and visualized under a $40 \times$ immersed objective with GFP filter.

Neurons were held at $-70 \mathrm{mV}$ across all voltage-clamp recordings. $\mathrm{GABA}_{\mathrm{A}}$ receptor $\left(\mathrm{GABA}_{\mathrm{A}} \mathrm{R}\right)$-mediated inhibitory postsynaptic currents (IPSCs) were pharmacologically isolated during recordings by adding kynurenic acid $(3 \mathrm{mM})$ to the bath solution to block AMPA and NMDA receptor-dependent postsynaptic currents. Recording electrodes were filled with (in mM) $70 \mathrm{KCl}, 65 \mathrm{~K}^{+}$-gluconate, $5 \mathrm{NaCl}, 10 \mathrm{HEPES}, 2 \mathrm{QX}-314,0.6 \mathrm{EGTA}, 4$ Na-ATP, 0.4 Na-GTP, pH 7.25, 290-295 mOsmol. Glutamatergic excitatory postsynaptic currents (EPSCs) were isolated by adding picrotoxin $(25 \mu \mathrm{M})$ to the bath solution to block $\mathrm{GABA}_{\mathrm{A}} \mathrm{R}$-mediated currents. Recording electrodes were filled with (in $\mathrm{mM}$ ) 117 gluconic acid, 20 HEPES, 0.4 EGTA, 5 TEA, 2 MgCl2, 2 QX-314, 4 Na-ATP, 0.4 Na-GTP, pH 7.3, 290-295 mOsmol. Miniature IPSCs and EPSCs were isolated by including tetrodotoxin (500 $\mathrm{nM}$ ) in the bath solution. For experiments examining the effects of LeuPro NPY on exogenously-applied GABA, kynurenic acid $(3 \mathrm{mM})$ was included in the extracellular solution and delivery of GABA $(100 \mu \mathrm{M})$ was directly administered to the synapse with a picospritzer. Experiments to functionally confirm DREADDs were performed in currentclamp configuration using a KGluc-based intracellular solution containing (in mM) $135 \mathrm{~K}$ Gluc, $5 \mathrm{NaCl}, 2 \mathrm{MgCl}^{2}$, 10 HEPES, 0.6 EGTA, 4 Na-ATP, and 0.4 Na-GTP. Signals were acquired via a Multiclamp 700B amplifier and analyzed using Clampfit 10.3 software (Molecular Devices, Sunnyvale, CA). Bath-applied drugs were diluted in bath aCSF from stocked frozen aliquots, and intracellular drugs were diluted to working concentrations directly in the intracellular recording solution. Cells were allowed to equilibrate to the recording pipette and intracellular solution for at least $30 \mathrm{~min}$ before recordings began. Input resistance and access resistance were continuously monitored during all experiments, and those in which changes in access resistance were greater than $20 \%$ were not included in the data analysis. 


\section{Drugs and viral vectors}

The following drugs used in microinfusion and electrophysiology experiments were obtained from Tocris/R\&D Biosystems (Minneapolis, MN): [Leu31Pro34] --Neuropeptide Y (LeuPro NPY), Neuropeptide Y 13-36 (NPY 13-36), BIIE 0246, BIBP 3226 trifluoroacetate, 1-[6-[[(17/)-3-Methoxyestra-1,3,5(10)-trien-17-yl]amino]hexyl]-1Hpyrrole-2,5-dione (U73122), guanosine 5'-[ $\beta$-thio]diphosphate trilithium salt (GDP $\beta S$ ), PKA inhibitor fragment (6-22) amide (PKI), 1,2-bis(o-aminophenoxy)ethane- $\mathrm{N}, \mathrm{N}, \mathrm{N}^{\prime}, \mathrm{N}^{\prime}$ tetraacetic acid (BAPTA), and dynamin inhibitory peptide (DIP). The following drugs were obtained from Abcam (formerly Ascent; Cambridge, UK): NPY 13-36, SR95531 (GABAzine), kynurenic acid sodium salt, picrotoxin, tetrodotoxin citrate (TTX), and GABA. The following drugs were obtained from Sigma-Aldrich (St. Louis, MO): RpAdenosine $3^{\prime}, 5^{\prime}$-cyclic monophosphorothioate triethylammonium salt (Rp-cAMPs), Protein Kinase A Catalytic Subunit from bovine heart (cPKA), and lidocaine $N$-ethyl bromide. $N$ Ethylmaleimide (NEM) was obtained from Fisher Scientific (Waltham, MA), and Brefeldin A was purchased from Cell Signaling Technology, Inc. (Danvers, MA). The viral vectors AAV8-hSyn-DIO-hM4D $\left(\mathrm{G}_{\mathrm{i}}\right)$-mCherry (G $\mathrm{G}_{\mathrm{i}}$-DREADD), AAV8-hSyn-DIO-rM4D $\left(\mathrm{G}_{\mathrm{s}}\right)$ mCherry ( $\mathrm{G}_{\mathrm{s}}$-DREADD), and AAV8-hSyn-DIO-mCherry (control vector), which have been described elsewhere ${ }^{37}$, were obtained from the UNC Viral Vector Core. CNO was kindly given to us by Bryan Roth.

\section{RT-PCR}

We examined the expression of NPY, Y1R, and Y2R mRNA one day after the last binge ethanol drinking session using RT-PCR, with experimenters blind to experimental condition of the subjects, which were randomly assigned. Mice were anesthetized with isoflurane and decapitated. Brains were rapidly excised using ice-cold sterilized tools and immersed in icecold sterile RNase-free water. Brains were rapidly blocked into $1 \mathrm{~mm}$ coronal sections and frozen over dry ice. Bilateral punches of the BNST one $\mathrm{mm}$ in diameter were taken for each mouse and combined to provide one sample per mouse. Samples were stored at $-20{ }^{\circ} \mathrm{C}$ in RNAlater RNA stabilization reagent (Qiagen, Germantown, MD) until being processed by the UNC Genomics core. Cycle threshold (CT, the number of cycles required for the fluorescent signal to cross a set threshold) was determined for the reference gene, $\beta$-actin, and the target gene. Relative expression (RE) for each target gene was calculated from the following equation and then averaged across samples within each group: $\mathrm{RE}=$ $2^{-(\mathrm{Ct} \text { target gene }-\mathrm{Ct} \text { reference gene })}$

\section{Immunohistochemistry}

Mice were anesthetized with Avertin and then perfused intracardially with $0.01 \mathrm{M}$ phosphate buffer saline (PBS) followed by 4\% paraformaldehyde (PFA) in PBS. Brains were extracted and post-fixed for 24 hours in 4\% PFA, then rinsed twice with PBS and put in 30\% sucrose until saturated. Brains were hemisected and coronal slices $45 \mu \mathrm{m}$ in thickness containing the BNST were prepared using a Leica VT1200 vibratome (Leica Microsystems, Nussloch, Germany) for immunohistochemistry for NPY, Y1R, and Y2R. Specificity of all three antibodies have previously been established: the NPY antibody was verified with colocalization of green fluorescent protein (GFP) and NPY (>95\%) in NPY-sappphire-GFP 
transgenic mice ${ }^{49}$, and the $\mathrm{Y}_{1} \mathrm{R}^{30}$ and $\mathrm{Y} 2 \mathrm{R}^{50}$ antibodies have been shown to not react in knockout mice. All immunohistochemistry was performed and quantified by experimenters blind to the experimental conditions of the subjects.

We examined NPY-IR across the light cycle using previously described immunohistochemical methods ${ }^{36}$. All incubations were carried out at room temperature and with gentle agitation. Slices were first rinsed in PBS three times for $10 \mathrm{~min}$, incubated in $50 \%$ methanol for $30 \mathrm{~min}$ and then $3 \%$ hydrogen peroxide for $5 \mathrm{~min}$ to quench endogenous peroxidases, and then rinsed in PBS three more times. Slices were incubated in PBS containing $0.5 \%$ Triton $\mathrm{X}-100$ for $30 \mathrm{~min}$, rinsed with PBS, and incubated in a blocking solution of PBS containing $0.1 \%$ Triton X-100 and 10\% normal donkey serum for 60 min. Slices were then directly transferred to the blocking solution also containing a 1:1,250 concentration of anti-NPY made in rabbit (Abcam catalog \#ab10980, Cambridge, UK) overnight. Slices were rinsed with PBS three times, incubated in a secondary solution containing anti-rabbit Alexa Fluor 488 made in donkey (Jackson ImmunoResearch Laboratories, catalog \#711-545-152, West Grove, PA) in PBS for 2 hrs, and rinsed in PBS four times. Slices were mounted onto glass slides, allowed to dry, coverslipped with VectaShield (Vector Labs, Burlingame, CA), and stored in the dark at $4{ }^{\circ} \mathrm{C}$.

We also examined protein expression of NPY, Y1R, and Y2R after binge alcohol drinking. Immunhistochemical protocols were carried out as previously described ${ }^{20}, 36$. For Y1R-IR, slices were rinsed in PBS, blocked in 10\% goat serum and 0.1\% Triton-X-100 in PBS for 1 $\mathrm{h}$, and then transferred to PBS containing a 1:25,000 concentration of anti-Y1R made in rabbit for $72 \mathrm{~h}$ at $4{ }^{\circ} \mathrm{C}$ (antibody 96106 raised against NPY Y1R was provided by CURE/ Digestive Disease Research Center, Antibody/RIA Core, Los Angeles, CA). After primary incubation, slices were rinsed in PBS and processed with Vectastain ABC Elite Kits (Vector Labs, Burlingame, CA) as per manufacturer's instructions. Sections were visualized by a reaction with 3,3'-diamino-benzidine (DAB, Polysciences Inc, catalog \#04001, Warrington, $\mathrm{PA}$ ) in a reaction solution containing $0.05 \% \mathrm{DAB}, 0.005 \%$ cobalt, $0.007 \%$ nickel ammonium sulfate, and $0.006 \%$ hydrogen peroxide.

For Y2R-IR, slices were incubated in primary solution containing $0.3 \%$ Triton $\mathrm{X}-100,0.5 \%$ bovine serum albumin, and a 1:3,000 concentration of anti-Y2R (Neuromics, catalog \#RA14112, Edina, MN) for $24 \mathrm{hrs}$ at $4^{\circ} \mathrm{C}$. Slices were washed in TNT buffer solution containing Tris/ $\mathrm{HCl}, \mathrm{NaCl}$, and Tween 20 for 10 minutes followed by TNB blocking solution containing TNT buffer with $0.5 \%$ blocking reagent provided in the TSA kit for 30 minutes. Slices were washed in TNB solution containing horseradish peroxidase (1:200) for 30 minutes and rinsed in TNT buffer. Sections were incubated in Cy3 (1:50) in amplification diluents provided in the TSA kit for 10 minutes and then rinsed in TNT buffer. All slices were mounted onto glass slides, allowed to dry, coverslipped with VectaShield, and stored in the dark at $4{ }^{\circ} \mathrm{C}$.

Images of the BNST from were obtained using a Nikon E400 microscope with a Nikon Digital Sight DS-U1 digital camera with Nikon-provided software or an Olympus FV1000 inverted confocal microscope and Olympus FluoView Software. IR intensity was analyzed by a researcher blind to conditions using Image J Software (Image J, National Institute of 
Health, Bethesda, MD) by calculating the percentage of the total area studied that showed staining relative to subthreshold background. For each mouse, values obtained for each slice were averaged to produce one value per mouse.

\section{Statistical analysis}

All data collection and analysis occurred by experimenters blind to the experimental conditions of the subjects, which were randomly or pseudo-randomly assigned to treatment groups as described in each section. Raw and baseline values for all data sets were tested for normal distribution and equal variances. Appropriate parametric statistical analyses were performed in GraphPad Prism when assumptions of normal distribution and equal variances were met; corrections for unequal variances, particularly Welch's correction, were used when necessary. Differences between control and experimental groups in behavioral pharmacology experiments were evaluated with unpaired t-tests. Behavioral effects of activation of DREADD viruses were analyzed using $2 \times 2$ repeated measures ANOVAs (control vs. DREADD vector, baseline vs. CNO as a repeated measure), with direct post-hoc Sidak's multiple comparisons t-tests when ANOVA interactions were significant. Effects of drugs during electrophysiological recordings were evaluated via paired t-tests between average values for each cell during baseline and washout periods, defined as the 6 min prior to and after the $10 \mathrm{~min}$ drug application. No statistical methods were used to predetermine sample sizes but our sample sizes are consistent with those previously published by our and other labs in the field ${ }^{13,20,36}$. All values given for electrophysiological measures, IR, and drug effects were normally distributed and are presented as mean \pm S.E.M.

\section{Supplementary Material}

Refer to Web version on PubMed Central for supplementary material.

\section{Acknowledgments}

We thank Stephanie Chien for assistance with histological verification of DREADD virus and cannulae placements, Rhiannon Thomas and Gretchen Sprow for help with drinking behavior experiments, and Bryan Roth for viral constructs and CNO. This work was supported by: AA021043 to KEP; AA019454, AA020911, and AA011605 to TLK; AA013573 and AA022048 to TET; AA013541 and AA109431 to KAG; DK071561 to DPO; DK075632, DK096010, DK046200 and DK057521 to BBL, and the Bowles Center for Alcohol Studies.

\section{References}

1. Lindell SG, et al. Functional NPY variation as a factor in stress resilience and alcohol consumption in rhesus macaques. Arch Gen Psychiatry. 2010; 67:423-431. [PubMed: 20368518]

2. Barr CS, et al. CRH haplotype as a factor influencing cerebrospinal fluid levels of corticotropinreleasing hormone, hypothalamic-pituitary-adrenal axis activity, temperament, and alcohol consumption in rhesus macaques. Arch Gen Psychiatry. 2008; 65:934-944. [PubMed: 18678798]

3. Ilveskoski E, et al. Association of neuropeptide y polymorphism with the occurrence of type 1 and type 2 alcoholism. Alcohol Clin Exp Res. 2001; 25:1420-1422. [PubMed: 11696660]

4. Chen AC, et al. Single-nucleotide polymorphisms in corticotropin releasing hormone receptor 1 gene (CRHR1) are associated with quantitative trait of event-related potential and alcohol dependence. Alcohol Clin Exp Res. 2010; 34:988-996. [PubMed: 20374216]

5. Koob GF. A role for brain stress systems in addiction. Neuron. 2008; 59:11-34. [PubMed: 18614026] 
6. Bonomo YA, Bowes G, Coffey C, Carlin JB, Patton GC. Teenage drinking and the onset of alcohol dependence: a cohort study over seven years. Addiction. 2004; 99:1520-1528. [PubMed: 15585043]

7. Jennison KM. The short-term effects and unintended long-term consequences of binge drinking in college: a 10-year follow-up study. Am J Drug Alcohol Abuse. 2004; 30:659-684. [PubMed: 15540499]

8. Saha TD, Stinson FS, Grant BF. The role of alcohol consumption in future classifications of alcohol use disorders. Drug Alcohol Depend. 2007; 89:82-92. [PubMed: 17240085]

9. Koob GF. Alcoholism: allostasis and beyond. Alcohol Clin Exp Res. 2003; 27:232-243. [PubMed: 12605072]

10. Heilig M. The NPY system in stress, anxiety and depression. Neuropeptides. 2004; 38:213-224. [PubMed: 15337373]

11. Hansson AC, Rimondini R, Neznanova O, Sommer WH, Heilig M. Neuroplasticity in brain reward circuitry following a history of ethanol dependence. Eur J Neurosci. 2008; 27:1912-1922. [PubMed: 18412612]

12. Heilig M, Koob GF. A key role for corticotropin-releasing factor in alcohol dependence. Trends Neurosci. 2007; 30:399-406. [PubMed: 17629579]

13. Kash TL, Winder DG. Neuropeptide Y and corticotropin-releasing factor bi-directionally modulate inhibitory synaptic transmission in the bed nucleus of the stria terminalis. Neuropharmacology. 2006; 51:1013-1022. [PubMed: 16904135]

14. Valdez GR, Koob GF. Allostasis and dysregulation of corticotropin-releasing factor and neuropeptide Y systems: implications for the development of alcoholism. Pharmacol Biochem Behav. 2004; 79:671-689. [PubMed: 15582675]

15. Valdez GR, Sabino V, Koob GF. Increased anxiety-like behavior and ethanol self-administration in dependent rats: reversal via corticotropin-releasing factor- 2 receptor activation. Alcohol Clin Exp Res. 2004; 28:865-872. [PubMed: 15201629]

16. Roberto $\mathrm{M}$, et al. Corticotropin releasing factor-induced amygdala gamma-aminobutyric Acid release plays a key role in alcohol dependence. Biol Psychiatry. 2010; 67:831-839. [PubMed: 20060104]

17. Sommer WH, et al. Upregulation of voluntary alcohol intake, behavioral sensitivity to stress, and amygdala crhr1 expression following a history of dependence. Biol Psychiatry. 2008; 63:139-145. [PubMed: 17585886]

18. Lowery-Gionta EG, et al. Corticotropin releasing factor signaling in the central amygdala is recruited during binge-like ethanol consumption in C57BL/6J mice. J Neurosci. 2012; 32:34053413. [PubMed: 22399763]

19. Heilig M, Soderpalm B, Engel JA, Widerlov E. Centrally administered neuropeptide Y (NPY) produces anxiolytic-like effects in animal anxiety models. Psychopharmacology (Berl). 1989; 98:524-529. [PubMed: 2570434]

20. Sparrow AM, et al. Central neuropeptide Y modulates binge-like ethanol drinking in C57BL/6J mice via Y1 and Y2 receptors. Neuropsychopharmacology. 2012; 37:1409-1421. [PubMed: 22218088]

21. Zhang H, et al. Neuropeptide Y signaling in the central nucleus of amygdala regulates alcoholdrinking and anxiety-like behaviors of alcohol-preferring rats. Alcohol Clin Exp Res. 2010; 34:451-461. [PubMed: 20028368]

22. Koob GF. Brain stress systems in the amygdala and addiction. Brain Res. 2009; 1293:61-75. [PubMed: 19332030]

23. Silberman Y, Winder DG. Emerging role for corticotropin releasing factor signaling in the bed nucleus of the stria terminalis at the intersection of stress and reward. Front Psychiatry. 2013; 4:42. [PubMed: 23755023]

24. Eiler WJ 2nd, Seyoum R, Foster KL, Mailey C, June HL. D1 dopamine receptor regulates alcoholmotivated behaviors in the bed nucleus of the stria terminalis in alcohol-preferring $(\mathrm{P})$ rats. Synapse. 2003; 48:45-56. [PubMed: 12557272]

25. Hyytia P, Koob GF. GABAA receptor antagonism in the extended amygdala decreases ethanol self-administration in rats. Eur J Pharmacol. 1995; 283:151-159. [PubMed: 7498304] 
26. Kash TL, Baucum AJ 2nd, Conrad KL, Colbran RJ, Winder DG. Alcohol exposure alters NMDAR function in the bed nucleus of the stria terminalis. Neuropsychopharmacology. 2009; 34:2420 2429. [PubMed: 19553918]

27. McElligott ZA, Winder DG. Modulation of glutamatergic synaptic transmission in the bed nucleus of the stria terminalis. Prog Neuropsychopharmacol Biol Psychiatry. 2009; 33:1329-1335. [PubMed: 19524008]

28. Thiele TE, Crabbe JC, Boehm SL 2nd. "Drinking in the Dark" (DID): a simple mouse model of binge-like alcohol intake. Curr Protoc Neurosci. 2014; 68(9):49 41-49 49 12. [PubMed: 24984686]

29. Molosh AI, et al. NPY Y1 receptors differentially modulate GABAA and NMDA receptors via divergent signal-transduction pathways to reduce excitability of amygdala neurons. Neuropsychopharmacology. 2013; 38:1352-1364. [PubMed: 23358240]

30. Kopp J, et al. Expression of the neuropeptide Y Y1 receptor in the CNS of rat and of wild-type and Y1 receptor knock-out mice. Focus on immunohistochemical localization. Neuroscience. 2002; 111:443-532. [PubMed: 12031341]

31. Rhodes JS, Best K, Belknap JK, Finn DA, Crabbe JC. Evaluation of a simple model of ethanol drinking to intoxication in C57BL/6J mice. Physiol Behav. 2005; 84:53-63. [PubMed: 15642607]

32. Calza L, et al. Daily changes of neuropeptide Y-like immunoreactivity in the suprachiasmatic nucleus of the rat. Regul Pept. 1990; 27:127-137. [PubMed: 2408111]

33. Parker SL, et al. Cloned neuropeptide Y (NPY) Y1 and pancreatic polypeptide Y4 receptors expressed in Chinese hamster ovary cells show considerable agonist-driven internalization, in contrast to the NPY Y2 receptor. Eur J Biochem. 2001; 268:877-886. [PubMed: 11179953]

34. Grant KA, et al. Drinking typography established by scheduled induction predicts chronic heavy drinking in a monkey model of ethanol self-administration. Alcohol Clin Exp Res. 2008; 32:18241838. [PubMed: 18702645]

35. Sparta DR, et al. Blockade of the corticotropin releasing factor type 1 receptor attenuates elevated ethanol drinking associated with drinking in the dark procedures. Alcohol Clin Exp Res. 2008; 32:259-265. [PubMed: 18162072]

36. Pleil KE, et al. Chronic stress alters neuropeptide $\mathrm{Y}$ signaling in the bed nucleus of the stria terminalis in DBA/2J but not C57BL/6J mice. Neuropharmacology. 2012; 62:1777-1786. [PubMed: 22182779]

37. Li H, et al. Experience-dependent modification of a central amygdala fear circuit. Nat Neurosci. 2013; 16:332-339. [PubMed: 23354330]

38. Cippitelli A, et al. Pharmacological blockade of corticotropin-releasing hormone receptor 1 (CRH1R) reduces voluntary consumption of high alcohol concentrations in non-dependent Wistar rats. Pharmacol Biochem Behav. 2012; 100:522-529. [PubMed: 22036774]

39. Ron D, Messing RO. Signaling pathways mediating alcohol effects. Curr Top Behav Neurosci. 2013; 13:87-126. [PubMed: 21877259]

40. Sparta DR, et al. Binge Ethanol-Drinking Potentiates Corticotropin Releasing Factor R1 Receptor Activity in the Ventral Tegmental Area. Alcohol Clin Exp Res. 2013

41. Melis M, Camarini R, Ungless MA, Bonci A. Long-lasting potentiation of GABAergic synapses in dopamine neurons after a single in vivo ethanol exposure. J Neurosci. 2002; 22:2074-2082. [PubMed: 11896147]

42. Moore EM, et al. GABAergic modulation of binge-like ethanol intake in C57BL/6J mice. Pharmacol Biochem Behav. 2007; 88:105-113. [PubMed: 17698181]

43. Borghese CM, Harris RA. Alcohol Dependence and Genes Encoding alpha2 and gamma1 GABAA Receptor Subunits: Insights from Humans and Mice. Alcohol Res. 2012; 34:345-353. [PubMed: 23134051]

44. Cox BR, et al. Repeated Cycles of Binge-Like Ethanol (EtOH)-Drinking in Male C57BL/6J Mice Augments Subsequent Voluntary EtOH Intake But Not Other Dependence-Like Phenotypes. Alcohol Clin Exp Res. 2013

45. Pandey SC, Carr LG, Heilig M, Ilveskoski E, Thiele TE. Neuropeptide y and alcoholism: genetic, molecular, and pharmacological evidence. Alcohol Clin Exp Res. 2003; 27:149-154. [PubMed: 12605064] 
46. Gilpin NW, et al. Neuropeptide Y opposes alcohol effects on gamma-aminobutyric acid release in amygdala and blocks the transition to alcohol dependence. Biol Psychiatry. 2011; 69:1091-1099. [PubMed: 21459365]

47. Krashes MJ, et al. An excitatory paraventricular nucleus to AgRP neuron circuit that drives hunger. Nature. 2014; 507:238-242. [PubMed: 24487620]

48. Helms CM, et al. The effects of age at the onset of drinking to intoxication and chronic ethanol self-administration in male rhesus macaques. Psychopharmacology (Berl). 2014; 231:1853-1861. [PubMed: 24448900]

49. Pinto S, et al. Rapid rewiring of arcuate nucleus feeding circuits by leptin. Science. $2004 ; 304: 110$ 115. [PubMed: 15064421]

50. Brumovsky $\mathrm{P}$, et al. Neuropeptide $\mathrm{Y} 2$ receptor protein is present in peptidergic and nonpeptidergic primary sensory neurons of the mouse. J Comp Neurol. 2005; 489:328-348. [PubMed: 16025447] 


\section{a}
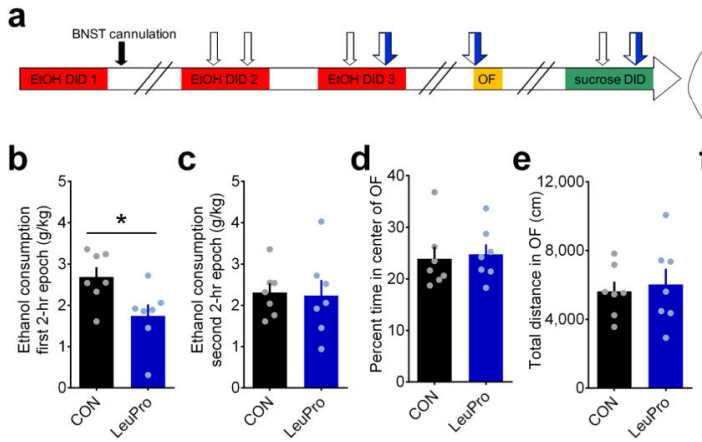

f
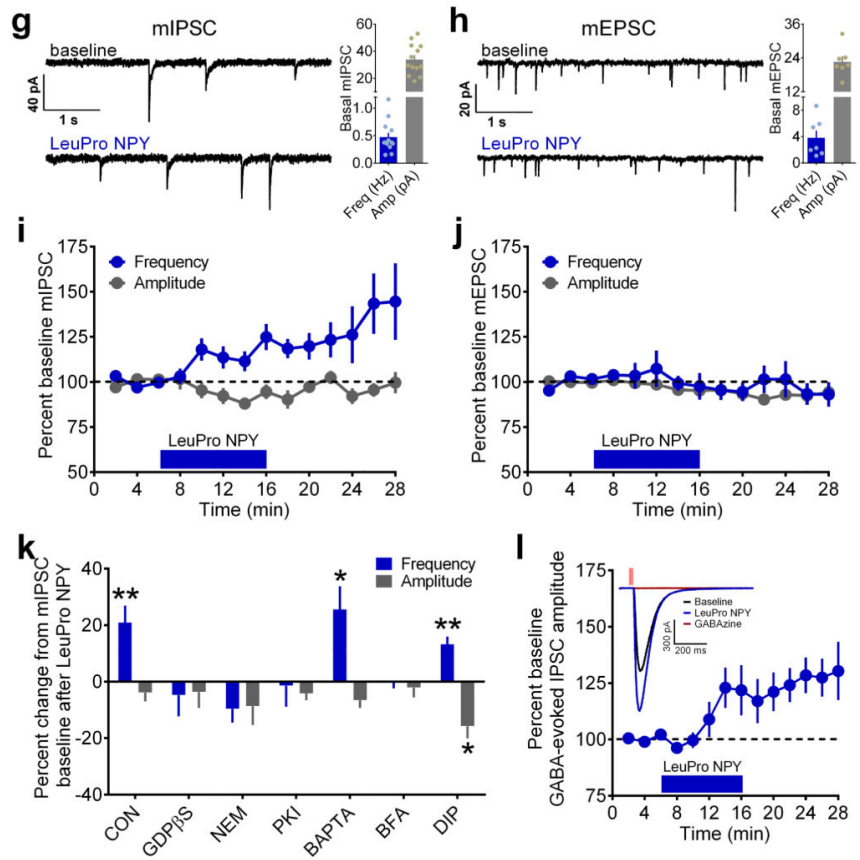

Figure 1.

Activation of $\mathrm{G}_{\mathrm{i}}$-coupled $\mathrm{Y} 1 \mathrm{R}$ in the BNST reduces binge ethanol drinking and enhances GABAergic transmission via a PKA-dependent, postsynaptic insertion of $\mathrm{GABA}_{\mathrm{A}}$ receptors. (a) Experimental timeline for examination of bilateral intra-BNST infusions of the Y1R agonist LeuPro NPY (99 pmol/200 nL/side, $\mathrm{N}=7$ mice) or control vehicle (CON; $200 \mathrm{~nL} /$ side, $\mathrm{N}=7$ mice) on EtOH DID, open field test (OF), and sucrose DID. (b-f) All statistical comparisons were made using unpaired t-tests. Mice that received infusions of LeuPro NPY consumed significantly less ethanol than CON mice during the first 2-hr epoch $(\mathbf{b} ; \mathrm{t}(12)=$ $\left.2.59,{ }^{*} \mathrm{p}=0.024\right)$ but not the second $2-\mathrm{hr}$ epoch $(\mathbf{c} ; \mathrm{p}>0.85)$ of ethanol DID, but LeuPro NPY infusion did not alter measures of anxiety and locomotion in the open field test (OF), including the percent time spent in the center (d) and total distance traveled (e) of the OF, or sucrose consumption in sucrose DID (f; p's > 0.45). (g-h) Representative traces of miniature inhibitory postsynaptic currents (mIPSCs; $\mathbf{g}$ ) and excitatory postsynaptic currents (mEPSCs; h) in BNST neurons before and after 10 min bath application of LeuPro NPY (300 nM), and basal frequency and amplitude for neurons used in mPSC experiments. (i) LeuPro NPY increased mIPSC frequency $(20.9 \pm 6.1 \%$; paired t-test baseline vs. washout: $t(12)=3.42, p$ $=0.005 ; \mathrm{n}=13$ neurons, $\mathrm{N}=11$ mice) but did not alter mIPSC amplitude $(\mathrm{p}>0.20)$. (j) 
Conversely, LeuPro NPY produced a small decrease in the amplitude of mEPSCs $(-6.9 \pm$ 2.3\%; paired t-test: $\mathrm{t}(4)=2.99, \mathrm{p}=0.041 ; \mathrm{n}=5, \mathrm{~N}=3$ ) but did not alter mEPSC frequency (p > 0.60). (k) Inclusion of GDP $\beta S(1 \mathrm{mM} ; \mathrm{n}=7, \mathrm{~N}=4)$ to block postsynaptic GPCR activity, NEM $(50 \mu \mathrm{M} ; \mathrm{n}=5, \mathrm{~N}=3)$ to block Gi signaling, $\mathrm{PKI}(20 \mu \mathrm{M} ; \mathrm{n}=6, \mathrm{~N}=3)$ to block PKA signaling, and BFA ( $200 \mathrm{nM} ; \mathrm{n}=5, \mathrm{~N}=4)$ to prevent receptor trafficking to the membrane all blocked the ability of bath-applied LeuPro NPY to increase mIPSC frequency (paired t-tests baseline vs. washout: p's $>0.10)$, while BAPTA $(10 \mu \mathrm{M} ; \mathrm{t}(5)=3.12, * \mathrm{p}=$ $0.026 ; \mathrm{n}=6, \mathrm{~N}=5)$ to block calcium and $\operatorname{DIP}(2 \mathrm{mM} ; \mathrm{t}(5)=4.76, * * \mathrm{p}=0.005 ; \mathrm{n}=6, \mathrm{~N}=3)$ to block receptor endocytosis did not. LeuPro NPY decreased mIPSC amplitude only when DIP was in the intracellular solution (DIP: paired t-test: $t(5)=3.60,{ }^{*} \mathrm{p}=0.016$; others: $\mathrm{p}$ 's > 0.05). (l) LeuPro NPY ( $300 \mathrm{nM})$ increased the amplitude of the $\mathrm{GABA}_{\mathrm{A}} \mathrm{R}$-mediated current in response to picospritzed GABA $(100 \mu \mathrm{M})$ by $25.3 \pm 7.0 \%$; paired t-test baseline vs. washout: $(\mathrm{t}(8)=3.59, \mathrm{p}=0.007 ; \mathrm{n}=9, \mathrm{~N}=7)$; inset: representative traces illustrating the effect of LeuPro NPY and complete ablation of the postsynaptic current by the $\mathrm{GABA}_{\mathrm{A}} \mathrm{R}$ blocker GABAzine $(20 \mu \mathrm{M})$. All data in $\mathbf{b}-\mathbf{l}$ are presented as mean \pm SEM. 


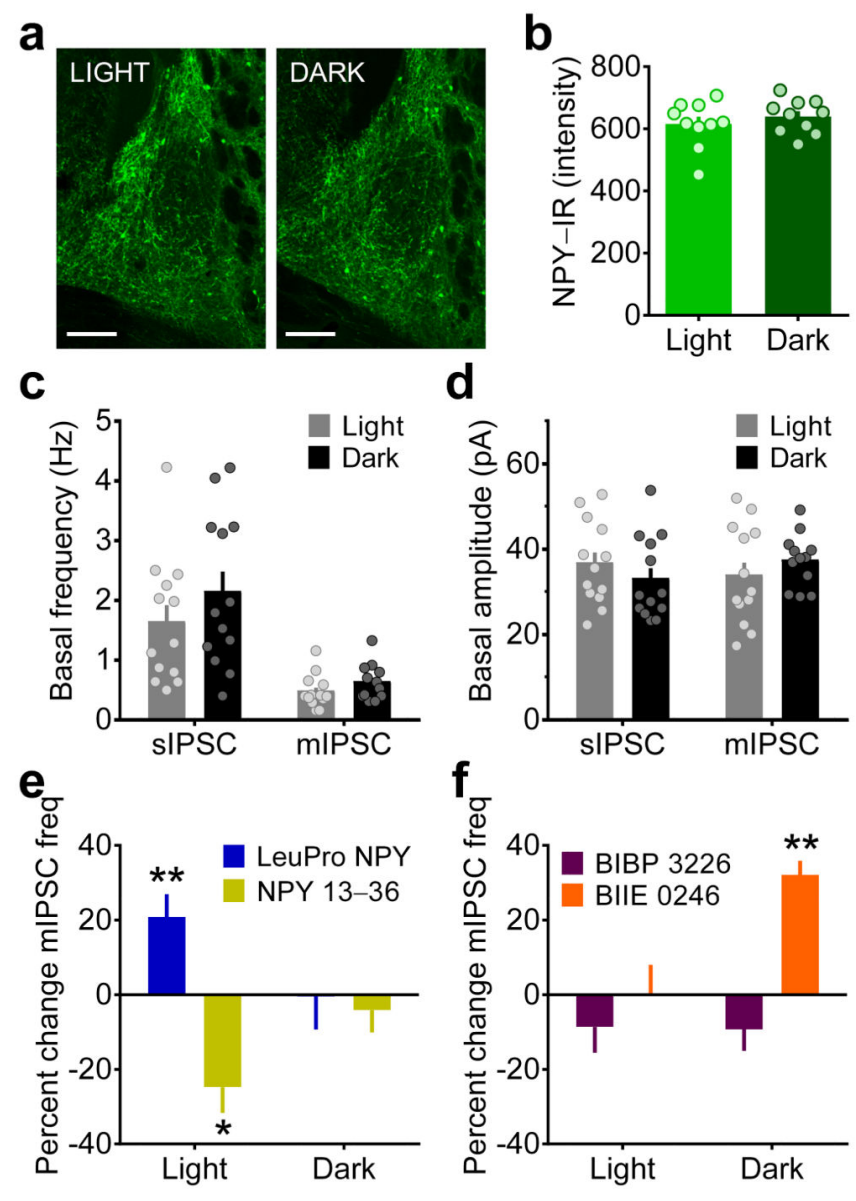

Figure 2.

Circadian regulation of receptor-specific NPY modulation of GABAergic transmission in the BNST. (a) Sample images representing mean NPY-IR in the BNST of mice sacrificed three hr into the light or dark phase of the light cycle (scale bars $=150 \mu \mathrm{M}$ ). Images shown were replicated for each individual data point shown in b. (b) Mean NPY-IR per mouse from five coronal slices (as in panel a) was not different between the light and dark phases of the light cycle (unpaired t-test: $p>0.40$; N's = 10/group). (c-d) Basal sIPSC and mIPSC frequency (c) and amplitude (d) were not different across the light cycle (unpaired t-tests: p's > 0.15; CON n = 13, N = 7, EtOH n = 13, N =7). (e) Bath application of LeuPro NPY (300 nM) increased, while the Y2R agonist NPY 13-36 (300 nM) decreased, mIPSC frequency during the light phase (LeuPro NPY: as shown in Fig. 1i, **p $=0.005$; NPY 1336: paired t-test baseline vs. washout: $\mathrm{t}(5)=3.57, * \mathrm{p}=0.016, \mathrm{n}=6, \mathrm{~N}=5$ ) but not the dark phase (p's > 0.15; LeuPro $n=5, N=4$, NPY 13-36 $n=6, N=4$ ), of the light cycle. (f) Bath application of the Y1R antagonist BIBP $3226(1 \mu \mathrm{M} ; \mathrm{n}=11, \mathrm{~N}=10)$ or the Y2R antagonist BIIE $0246(1 \mu \mathrm{M} ; \mathrm{n}=4, \mathrm{~N}=3)$ did not alter mIPSC frequency during the light phase (paired t-tests baseline vs. washout: p's > 0.20); BIIE 0246 increased mIPSC frequency during the dark phase $(\mathrm{t}(3)=8.45$, ** $\mathrm{p}=0.004 ; \mathrm{n}=4, \mathrm{~N}=3)$, while BIBP 3226 did not ( $\mathrm{p}>0.15 ; \mathrm{n}=$ $5, \mathbf{N}=4)$. All data in $\mathbf{b}-\mathbf{l}$ are presented as mean \pm SEM. 


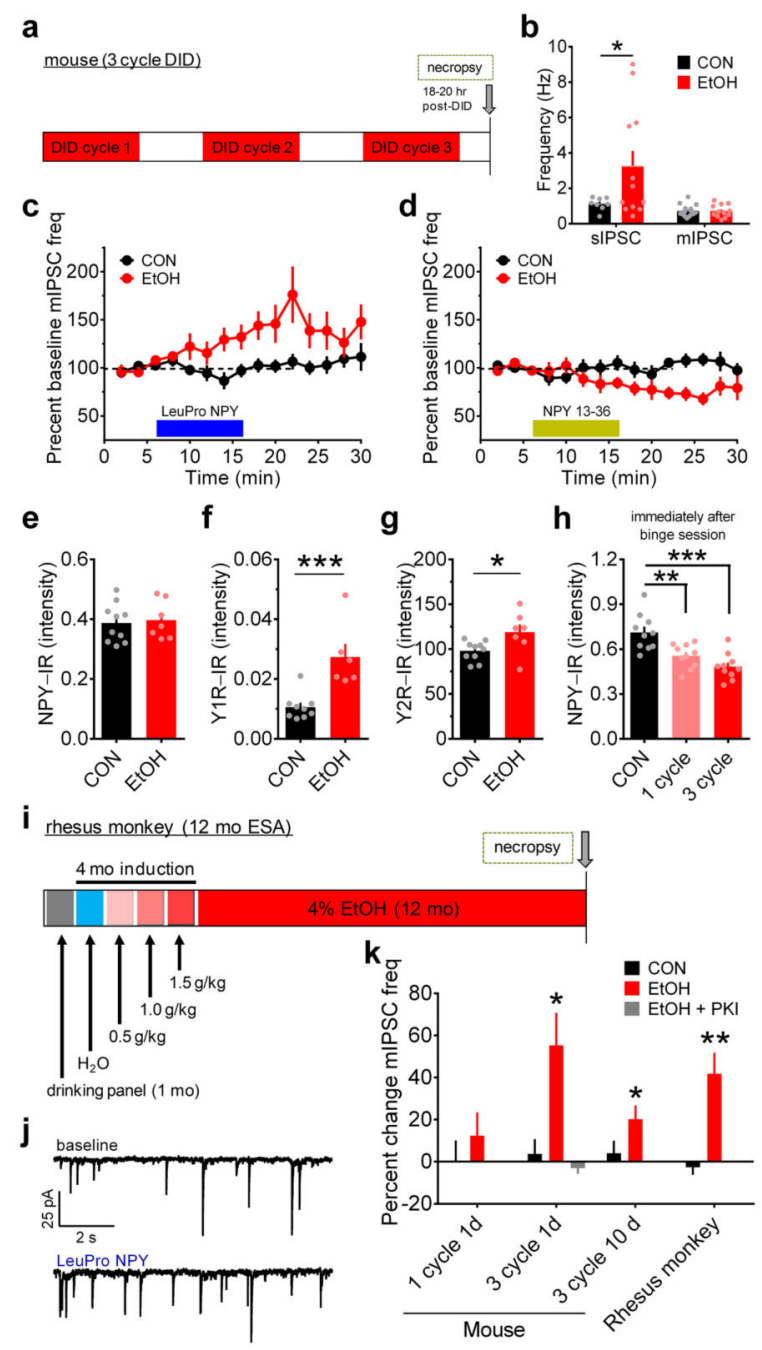

Figure 3.

Chronic binge alcohol drinking alters receptor-specific NPY modulation of GABAergic transmission in the BNST of mice and monkeys. (a) Experimental timeline for 3-cycle DID in mice. (b) BNST neurons from mice that drank ethanol (EtOH) had higher sIPSC frequency than water-drinking controls (CONs; unpaired t-test with Welch's correction: $\mathrm{t}(11)=2.32,{ }^{*} \mathrm{p}=0.040, \mathrm{CON} \mathrm{n}=8, \mathrm{~N}=5, \mathrm{EtOH} \mathrm{n}=12, \mathrm{~N}=5$ ), but mIPSC frequency did not differ between groups (unpaired t-test: $\mathrm{p}>0.95 ; \mathrm{CON} \mathrm{n}=15, \mathrm{~N}=7, \mathrm{EtOH} \mathrm{n}=12, \mathrm{~N}=$ 6). (c) LeuPro NPY ( $300 \mathrm{nM}$ ) significantly increased mIPSC frequency in EtOH mice (paired t-test baseline vs. washout: $\mathrm{t}(5)=3.58, \mathrm{p}=0.016 ; \mathrm{n}=6, \mathrm{~N}=6$ ) but not CONs ( $\mathrm{p}$ > $0.60, \mathrm{n}=7, \mathrm{~N}=7)$. (d) NPY 13-36 (300 nM) decreased mIPSC frequency in ethanoldrinking mice $(\mathrm{t}(5)=2.97, \mathrm{p}=0.031 ; \mathrm{n}=6, \mathrm{~N}=5)$ but not controls $(\mathrm{p}>0.85, \mathrm{n}=7, \mathrm{~N}=6)$. (e-g) Mean NPY-IR (average IR from 3-5 slices per mouse) was similar between groups (e; unpaired t-test: $\mathrm{p}>0.75 ; \mathrm{CON} \mathrm{N}=10, \mathrm{EtOH} \mathrm{N}=7)$, but Y1R-IR $(\mathbf{f} ; \mathrm{t}(13)=4.23$, ***p = 0.001; CON N = 9, EtOH N = 6) and Y2R-IR $\left(\mathrm{g} ; \mathrm{t}(15)=2.50,{ }^{*} \mathrm{p}=0.025 ; \mathrm{CON} \mathrm{N}=10\right.$, EtOH N = 7) were higher in the BNST of EtOH mice than CONs. (h) NPY-IR was significantly decreased in the BNST of EtOH mice compared to water-drinking CONs 
immediately after the last binge ethanol drinking exposure in 1-cycle and 3-cycle DID (N's $=10$ /group), but was not different between one and 3-cycle DID (one-way ANOVA: F $(2,27$ ) $=14.25, \mathrm{p}<0.0001$; post-hoc Sidak's multiple comparisons test: CON vs. 1-cycle: $\mathrm{t}(18)=$ $3.58, * * \mathrm{p}=0.004$; CON vs. 3 -cycle DID: $\mathrm{t}(18)=5.22, * * * \mathrm{p}<0.001 ; 1$-cycle DID vs. 3cycle DID: $p>0.25$ ), suggesting that NPY was similarly recruited acutely during each binge ethanol session across each cycle. (i) Experimental timeline for voluntary ethanol selfadministration (ESA; access to $4 \%$ ethanol for $22 \mathrm{~h} / \mathrm{d}, 7 \mathrm{~d} / \mathrm{wk}$ for $12 \mathrm{mo}$ ) in adult male rhesus monkeys. (j) Representative traces of mIPSCs from ethanol self-administering rhesus monkey BNST neurons before and after bath application of LeuPro NPY (300 nM). (k) mIPSC frequency was unaltered by LeuPro NPY following one cycle of DID in EtOH mice $(\mathrm{n}=8, \mathrm{~N}=4)$ and water-drinking $\mathrm{CONs}(\mathrm{n}=5, \mathrm{~N}=3$; paired t-tests baseline vs. washout: p's > 0.30), but it was increased in $\mathrm{EtOH}$, but not $\mathrm{CON}$, mice $1 \mathrm{~d}$ after the final binge session of 3-cycle EtOH DID, as shown in $\mathbf{c}$, which could be blocked by intracellular inclusion of PKI $(20 \mu \mathrm{M} ; \mathrm{p}>0.35 ; \mathrm{n}=3, \mathrm{~N}=2)$. The adaptation in LeuPro NPY modulation of mIPSC frequency was still present $10 \mathrm{~d}$ after the final binge ethanol session in EtOH mice $\left(\mathrm{t}(5)=3.09,{ }^{*} \mathrm{p}=0.027 ; \mathrm{n}=6, \mathrm{~N}=3\right)$ but not CONs $(\mathrm{p}>0.50, \mathrm{n}=5, \mathrm{~N}=3)$ and was also observed in rhesus monkeys after 12 mo of continuous access to ethanol $(\mathrm{t}(8)=4.21$, **p $=$ $0.003 ; n=9, N=5$ ) but not control solution ( $p>0.50 ; n=4, N=3$ ). All data in $\mathbf{b}-\mathbf{h}$ and $\mathbf{k}$ are presented as mean \pm SEM. 


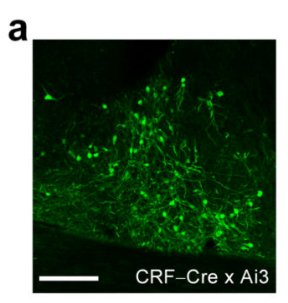

b
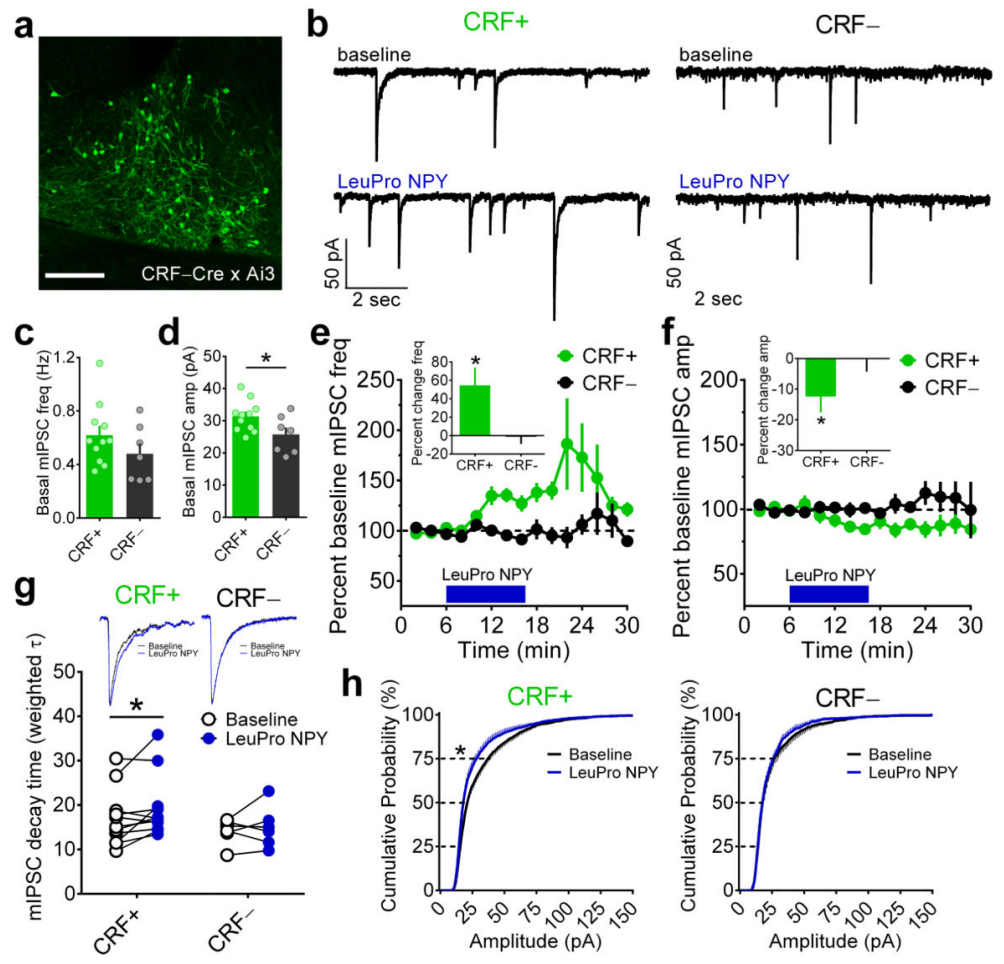

h
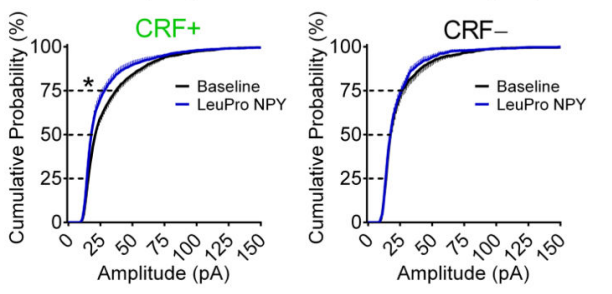

Figure 4.

Y1R-mediated effects on inhibition in the BNST are specific to CRF neurons. (a) Sample image of the dorsal BNST in a naïve $C R F-C r e \times \mathrm{Ai} 3$ reporter mouse taken from a coronal brain slice depicting $\mathrm{CRF}-\mathrm{Cre}$-positive neurons in green (scale bar $=150 \mu \mathrm{M}$ ). Fluorescence expression shown is typical in this mouse line and was confirmed for all mice used in experiments for panels b-h. (b) Representative traces of mIPSCs from $C R F-C r e$-positive $(\mathrm{CRF}+)$ and $\mathrm{CRF}-\mathrm{Cre}$-negative (CRF-) neurons in the BNST before and after bath application of LeuPro NPY (300 nM). (c-d) Basal mIPSC frequency did not differ in CRF+ and CRF- BNST neurons (unpaired t-test: $\mathrm{p}>0.20 ; \mathrm{CRF}+\mathrm{n}=11, \mathrm{~N}=6, \mathrm{CRF}-\mathrm{n}=7, \mathrm{~N}=4$ for all panels), but basal mIPSC amplitude was greater in CRF+ than CRF- neurons ( $\mathrm{t}(16)=$ $\left.2.25,{ }^{*} \mathrm{p}=0.039\right)$. (e) Bath application of LeuPro NPY increased mIPSC frequency in CRF+ neurons in the BNST by $54.7 \pm 19.3 \%$ (paired t-test baseline vs. washout: $\mathrm{t}(10)=2.83$, ${ }^{*} \mathrm{p}=$ 0.018 ) but did not alter mIPSC frequency in CRF- neurons $(-1.3 \pm 7.8 \% ; \mathrm{p}>0.85$; magnitude of average percent change in frequency depicted in inset bar graph). (f) LeuPro NPY slightly but significantly decreased mIPSC amplitude in CRF+ neurons $(-12.4 \pm 5.2 \%$; $\left.\mathrm{t}(10)=2.40,{ }^{*} \mathrm{p}=0.038\right)$ but did not alter mIPSC amplitude in CRF- neurons $(-0.1 \pm 4.2 \%$; $\mathrm{p}>0.95$; magnitude of effects depicted in inset bar graph). (g) Representative averaged traces (top) and weighted tau values (bottom) of CRF+ and CRF- neurons in the BNST before and after bath application of LeuPro NPY showing that LeuPro NPY increased the decay magnitude of mIPSCs in CRF+ neurons (paired t-test: $t(10)=2.40, * p=0.037$ ) but did not alter the decay of mIPSC events in CRF- neurons ( $p>0.50)$; rise time of mIPSCs was not altered in either group (p's $>0.10$, data not shown). (h) Cumulative probability distributions of mIPSC amplitude showing that there was a leftward shift in the distribution by the $75^{\text {th }}$ percentile of events in $\mathrm{CRF}+$ neurons (paired t-test: $\mathrm{t}(10)=2.34,{ }^{*} \mathrm{p}=0.041$ ), 
indicating that application of LeuPro NPY led to a greater number of mIPSC with smaller amplitude, while there was no effect on the distribution of mIPSC amplitude in CRFneurons ( $p$ 's $>0.45$ ). All data in $\mathbf{c}-\mathbf{h}$ are presented as mean \pm SEM. 


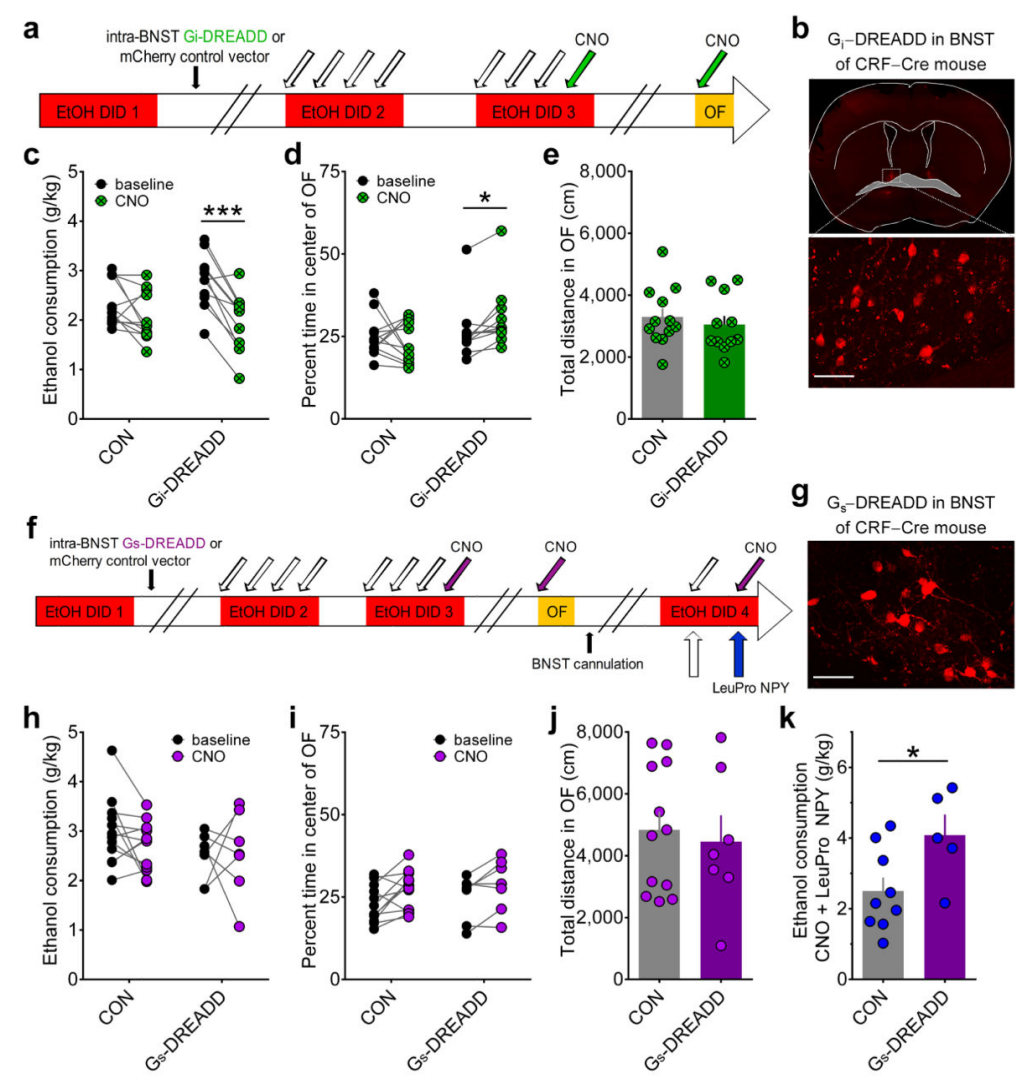

Figure 5.

Direct in vivo chemogenetic activation of $\mathrm{G}_{\mathrm{i}}$ signaling in BNST CRF neurons recapitulates, while chemogenetic activation of $\mathrm{G}_{\mathrm{s}}$ signaling blocks, the effect of Y1R activation on binge ethanol consumption. (a) Experimental timeline for examination of behavioral effects of in vivo DREADD activation of $\mathrm{G}_{\mathrm{i}}$ signaling in BNST CRF neurons in CRF-Cre mice (vehicle = white arrows, $\mathrm{CNO}(3 \mathrm{mg} / \mathrm{kg})=$ green arrows $)$. (b) Representative image of a coronal slice containing BNST from a CRF-Cre mouse following microinjection of the AAV8-hSynDIO-hM4D-mCherry ( $\mathrm{G}_{\mathrm{i}}$-DREADD) into the BNST and behavioral testing described in panel a (scale bar $=50 \mu \mathrm{m})$. Similar expression was confirmed for all mice in $\mathbf{c}-\mathbf{e}$. $(\mathbf{c}) \mathrm{CNO}$ administration produced a decrease in binge ethanol consumption in DID compared to baseline in CRF-Cre mice with the $\mathrm{G}_{\mathrm{i}}$-DREADD $(\mathrm{N}=11$ for panels $\mathbf{b}-\mathbf{e})$ but not the control vector AAV8-hSyn-DIO-mCherry (CON; $\mathrm{N}=12$ for panels $\mathbf{b}-\mathbf{e})$, in the BNST $(2 \times 2$ repeated measures ANOVA: main effect of CNO $(\mathrm{F}(1,21)=29.8, \mathrm{p}<0.0001)$ and significant interaction between $\mathrm{G}_{\mathrm{i}}$-DREADD condition and $\mathrm{CNO}(\mathrm{F}(1,21)=7.27, \mathrm{p}=$ 0.014); post-hoc t-tests: significant difference between baseline and $\mathrm{CNO}$ for the $\mathrm{G}_{\mathrm{i}^{-}}$ DREADD mice $(\mathrm{t}(10)=6.24, * * * \mathrm{p}<0.0001)$ but not the CON vector mice $(\mathrm{p}>0.10))$. (d) $\mathrm{CNO}$ administration produced an increase in the percent time spent in the center of the OF in CRF-Cre mice with the $\mathrm{G}_{\mathrm{i}}$-DREADD, but not the control vector, in the BNST $(2 \times 2$ repeated measures ANOVA: significant interaction between $\mathrm{G}_{\mathrm{i}}$-DREADD condition and CNO $(F(1,21)=4.48, p=0.047)$; post-hoc t-test: significant difference between baseline and $\mathrm{CNO}$ for the $\mathrm{G}_{\mathrm{i}}$-DREADD mice $(\mathrm{t}(10)=3.15$, $* \mathrm{p}=0.010)$ but not the CON vector mice $(\mathrm{p}>0.65)$ ). (e) $\mathrm{G}_{\mathrm{i}}$-DREADD and CON mice did not differ in their locomotor behavior 
(unpaired t-test: p > 0.50). (f) Experimental timeline for examination of behavioral effects of in vivo DREADD activation of $\mathrm{G}_{\mathrm{s}}$ signaling in BNST CRF neurons in CRF-Cre mice and interaction between Gs-DREADD and LeuPro NPY (vehicle $=$ white arrows, CNO (3 $\mathrm{mg} / \mathrm{kg})=$ purple arrows, LeuPro NPY $(99 \mathrm{pmol} / 200 \mathrm{~nL} /$ side $)=$ blue arrows $).(\mathrm{g})$ Representative image showing expression of the AAV8-hSyn-DIO-rM3D-mCherry $\left(\mathrm{G}_{\mathrm{s}}\right.$ DREADD) in the BNST of a CRF-Cre mouse that underwent behavioral testing (scale bar = $50 \mu \mathrm{m}$ ). Similar expression was confirmed for all mice in $\mathbf{h}-\mathbf{k}$. (h) CNO administration did not alter binge ethanol consumption in either the $\mathrm{CON}(\mathrm{N}=12)$ or $\mathrm{G}_{\mathrm{s}}-\mathrm{DREADD}(\mathrm{N}=7)$ groups ( 2 × 2 repeated measures ANOVA: p's $>0.15)$. $\mathbf{i}-\mathbf{j})$ While there was a main effect of $\mathrm{CNO}$ in the percent time spent in the center of the $\mathrm{OF}$ with a $2 \times 2$ repeated measures ANOVA (i; $F(1,17)=9.92, p=0.006)$, there was no main effect of DREADD group or interaction (p's > 0.50), and there was no difference between CON and $\mathrm{G}_{\mathrm{s}}$-DREADD mice in locomotor behavior ( $\mathbf{j}$; unpaired t-test: $\mathrm{p}>0.70$ ). (k) Activation of the $\mathrm{G}_{\mathrm{s}}$-DREADD blocked the Y1R-mediated suppression of drinking (unpaired t-test: $\mathrm{t}(12)=2.36,{ }^{*} \mathrm{p}=0.036$; CON N $=9, \mathrm{G}_{\mathrm{s}}$-DREADD $\mathrm{N}=5$ ), suggesting that activation of PKA signaling is sufficient to prevent the behavioral effect of Y1R-mediated inhibition of PKA signaling. Data in $\mathbf{e}, \mathbf{j}$, and $\mathbf{k}$ are presented as mean \pm SEM. 